\title{
A Review on Polysaccharide Based Nanocomposite Hydrogel Systems Fabrication Using Diverse Reinforcing Materials
}

\author{
Nisha Sharma ${ }^{1, *}$,Vikrant Singh Rana ${ }^{2,3}$ \\ ${ }^{1}$ Assistant Professor, Department of Physical Sciences, Sant Baba Bhag Singh University, Jalandhar, \\ Punjab, India \\ ${ }^{2}$ Research Scholar, Department of Physical Sciences, Sant Baba Bhag Singh University, Jalandhar, \\ Punjab, India \\ ${ }^{3}$ Assistant Professor, Department of Chemistry, Sri Guru Gobind Singh Khalsa College Mahilpur, \\ Hoshiarpur, Punjab, India
}

\begin{abstract}
In the current scenario, materials with better physicochemical properties are desirable to achieve quality life and sustainability. Polysaccharide/biopolymeric based hydrophilic systems owning to their inherent properties, especially hydrophilicity, nontoxicity and biocompatibility have extended their approach in every strata of biomedical sciences and replaced synthetic polymers upto great extent. Despite this, they have also experienced certain demerits due to their biological origin. Functionalization of polysaccharide based hydrophilic polymer with reinforcing materials/modulators, especially in nano-dimensions, is one of such approach getting much attention in current scenario. Although great deal of work has been published in nanocomposite hydrogels but least attention was paid for polysaccharide based nanocomposite hydrophilic systems. Present study is an attempt to compile a brief account of fabrication of polysaccharide based nanocomposites using metallic nanoparticles, metallic oxides, CNT and graphene, and clay as nanofillers with improved physicochemical as well as biological properties.
\end{abstract}

Keywords: Hydrogel, nanocomposite hydrogel, functionalization, reinforcing materials, physicochemical properties, nanofillers, sustainability

*Author for Correspondence E-mail: nishi.hpu@gmail.com

\section{INTRODUCTION}

Since last century, polysaccharide based hydrophilic systems have revolutionized all sectors viz. biomedical, drug delivery, environmental and advanced industrial sectors due to their unique characteristics such as hydrophilicity, swelling ability, biodegradability, nontoxicity and biocompatibility. Apart from these properties, they possess certain demerits such as uncontrolled swelling profile, poor mechanical and tensile strength, and poor stability which limit their use for advanced applications where such behavior is desirable. From time to time, different strategies have been adopted to overcome such drawbacks. Composite hydrogels, graft copolymerization, and various other chemical treatment strategies have been adopted from time to time.
Fabrication of nanocomposite filled hydrophilic system is one of the most fascinating and advantageous approaches due to improved behavior of gel system without compromising the base properties of the system. Biopolymeric nanocomposite hydrogels are a class of homogeneous natural polymeric network prepared by reinforcement of the polymer matrix with nanoparticles imparting high tensile strength and high toughness compared to conventional hydrogel [1-5]. Natural, synthetic and combination of natural and synthetic polymers are used to form nanocomposite hydrogel matrix. Nanocomposite hydrogel can also be defined as water swollen materials composed of polymer matrix and nanoparticles, both organic and inorganic, metals, metal oxides, with clay as reinforcing 
materials into a biopolymeric base matrix. These materials improve the behavior of material in different aspects. Reinforcing materials are primarily in nano-scale dimensions and possess special characteristic attributes to their size which in turn modulate behavior of polymeric matrix. There are primarily covalent or physical interactions which bind the gel system and reinforcing materials together. There is a clear distinction among composite and nanocomposite hydrogels as the reinforcing material used in composite need not necessarily to be of controlled size but in nanocomposite, reinforcing material must have nano-scale dimensions and should have some distinct inherent behavior due to their size [6].

In literature, various polysaccharides such as alginate [7], chitosan [8-10], carrageenan [11, 12], cellulose and modified cellulose [13-15], gum acacia [16], guar gum $[17,18]$, xanthan gum [19, 20], starch and modified starch [21, $22]$, tragacanth gum[23, 24], and gum karaya $[25,26]$ have been modified using diverse class of reinforcing materials. Present study is intended to compile a brief account on different types of polysaccharides and different reinforcing materials used for synthesis of nanocomposite systems for advanced applications.

\section{Characteristics of Nanocomposite Hydrogels}

Polysaccharides based nanocomposite hydrogels possess mixture of properties such as biodegradability, biocompatibility, permeability, hydrophilicity, non-toxic, and non-immunogenic behavior owing to natural polymeric matrix and new/improved properties attributed to nanoparticles included with in which in turn increase the horizons of polysaccharide nanocomposite hydrophilic systems. They also possess ease of surface modification as compared to synthetic polymer matrix [27-29]. Nanocomposite hydrogels have enhanced mechanical strength, multifunctionalities [30] and multi-responsiveness [31] with zero dimensional scale, like fullerenes enhance mechanical strength of gel and impart photo responsiveness [32]. Onedimensional nanomaterials such as single wall and multiwalled carbon nanotubes when embedded in hydrogel networks improve their mechanical, thermal and electric properties [33, 34]. Two-dimensional graphene sheets when embedded in biopolymeric matrix improve specific surface area, mechanical stiffness, optical behavior and gas permeability [35]. Similarly, threedimensional nanoparticles, when incorporated, improve basic characteristics of polymeric systems, are also used in printing technology.

\section{TYPES OFBIOPOLYMERIC} NANOCOMPOSITE HYDROGELS ON THE BASIS OF REINFORCING MATERIALS

\section{Metal Nanoparticles Based Nanocomposite Hydrogels}

Metal nanoparticles are most demoralized reinforcing materials used for the fabrication of nanocomposite hydrogels. Most common metallic nanoparticles such as $\mathrm{Ag}, \mathrm{Au}, \mathrm{Cu}, \mathrm{Pt}$, $\mathrm{Ce}$ and $\mathrm{Fe}$ have been used for the synthesis of polysaccharide based nanocomposite hydrogels [36-41].

In literature, a great deal of work is dedicated for the incorporation of silver ion as nanoparticle owing to inherent antimicrobial property of silver thus helpful for the synthesis of biomedical systems. During fabrication of metallic nanoparticle embedded gel systems, different reducing systems are desirable as auxillary stabilizing systems such as strong reducing agents like sodium borohydride. Natural polysaccharide itself also acts as reducing and stabilizing system due to presence of different functionalities on the backbone. Plant extracts are also applicable as reducing systems. Ag-sodium alginate nanocomposite hydrogels when fabricated through single step green synthesis using Mukia maderaspatana plant extract as a reducing agent show improved chemical and physical properties [42]. Rao et al. have incorporated silver nanoparticles inside xanthum gum and chitosan based polysaccharide matrix without the use of any chemical reducing agent. Polysaccharide chain itself stabilizes the nanoparticle through ionic and dipole-dipole interaction [43]. Silver nanoparticles can also be incorporated through 
redox polymerization using vinylic monomers and N'N', Methylene bisacrylamide as crosslinking system in to a tragacanth gum based hydrogel matrix. Leaf extract of Terminalia chebula acts as reducing medium and nanoparticles were also stabilized as a result of hydrogen bonding with the functional groups present on the hydrogel matrix. These functionalities also attribute to swelling behavior of hydrogel networks [44]. Carboxymethyl tamarind (CMT) acts as reductant and capping agent for the amalgamation of silver nanoparticles. Base concentration of CMT and silver nitrate modulates the physical and chemical properties of the prepared nanocomposite hydrogel [45]. Chitosan-PVA polymer matrix embedded with $\mathrm{Ag}$ nanoparticles has been fabricated through freeze thaw method using glutaraldehyde as crosslinker. $\mathrm{NaBH}_{4}$ acts as reducing agent to convert silver ions in to silver nanoparticles. Concentration of the glutaraldehyde controls the size of silver nanoparticles. There is strong interaction among silver nanoparticles and polymer matrix which is reflected in terms of declined swelling capacity of the hydrogel [46]. Kristic et al. have also fabricated silver nanoparticles embedded chitosan/PVA polymer matrix by gamma irradiation. The nanoparticles were stabilized by interaction with the functional groups present on the polymer network. Composition of feed matrix system strongly influences the size and stability of nanoparticles which in turn control the physicochemical characteristics of the system [47].

In one pot reaction by Abdullah et al., Ag nanoparticles could be included inside guar gum in the presence of epichlorhydrin. The resultant nanocomposite films have low water permeability and were used in food packaging [48]. Polysaccharide embedded nanoparticles could be achieved through electrospinning method. Vellora et al. Have prepared $\mathrm{Ag}$ nanoparticles through chemical reduction of silver nitrate and subsequently embedded into Gum Karaya/PVA matrix by electrospinning. 80:20 ratio of $\mathrm{PVA} /$ Chitosan fabricated membranes display excellent physicochemical properties as well as with good antibacterial activity [49]. Djerahov fabricated Chitosan/Ag nanocomposite films using $\mathrm{D}-(+)$-raffinose as reducing and stabilizing agent. These films have good mechanical strength in aqueous solution.

There is narrow size distribution of nanoparticles with excellent homogeneity in shape as compared to silver nanoparticles prepared by other methods [50]. Ag nanoparticles can be incorporated into starch/PVA films fabricated through solvent casting method using UV light as reducing system. Elasticity modulus and tensile strength values have been enhanced at low silver concentration and decreased at high silver concentration [51]. Singh et al. have fabricated gum tragacanth, acacia gum, PVA and polyvinyl pyrollidone (PVP) based hydrogels films through radiation induced crosslinking method. Ag nanoparticles have been incorporated through swelling equilibrium method using $\mathrm{NaBH}_{4}$ as reducing agent. These hydrophilic networks have been used in wound dressing. Ag nanoparticles increase antioxidant properties along with inherent antimicrobial behavior. Concentration of acacia gum controls the release of the silver nanoparticles from the hydrogel network and thus facilitates release of silver ions for extended period of time [52]. Au nanoparticles when incorporated into chitosan polysaccharide matrix loaded with curcumin an anticancer drug resulted into a $\mathrm{pH}$ responsive gel networks [53]. Alginate/Acrylamide hydrogels loaded with iron nanoparticles results into photoresponsive hydrogels. The appearance of orange color indicated the incorporation of ferric ions into the hydrogel network. The photochemical treatment changed the microscopic and macroscopic behavior of the hydrogel [54]. Al-Enizi et al. prepared $\mathrm{Cu}$ nanoparticles embedded cellulose gum matrix using hydrazine as reducing system. Copper nanoparticles are stabilized through the interaction between the hydroxyl and carboxyl group functionalities of the gel matrix. Storage modulus of the nanocomposite hydrogel was found to be higher than loss modulus [55]. Gold alginate bio-nanocomposites have also been synthesized through impregnation of alginate films with $\mathrm{HAuCl}_{4}$ followed by reduction with glucose. Polymer concentration affects the thickness, amount of 
$\mathrm{Au}^{3+}$ trapped, and volume fraction of $\mathrm{Au}(0)$ [37]. Laudenslager et al. have synthesized $\mathrm{Au}, \mathrm{Ag}$ and $\mathrm{Pt}$ nanoparticles integrated native chitosan and carboxymethyl chitosan based nanocomposite gel matrix using $\mathrm{NaBH}_{4}$ as reducing system. Nanoparticle aggregation takes place inside carboxymethyl chitosan as compared to native chitosan where uniform distribution is obtained [39].

\section{Metal Oxides Based Nanocomposite Hydrogels}

Metal oxides are other reinforcing materials used for nanocomposite fabrication. They possess unique characteristics i.e. thermal stability, optical and photo-responsive behavior and when incorporated in nanodimensions into a polymeric matrix, inculcate same behavior into the gel system. $\mathrm{ZnO}$ nanoparticles based chitosan matrix can be synthesized through single step in-situ sol-gel method. $\mathrm{ZnO}$ drastically improves the thermal stability of Chitosan/ZnO as compared to chitosan hydrogel [56]. Chitosan/PVP nanocomposite films have been fabricated through incorporation of $\mathrm{AgO}$ nanoparticles by sodium citrate reduction. Concentration of $\mathrm{AgO}$ influences the size of nanoparticles inside the gel matrix without affecting the swelling ability [57]. $\mathrm{TiO}_{2} /$ Collagen-Chitosan scaffolds fabricated through freeze drying process, by Keke et al., possess good stability and permeability as compared to scaffold without $\mathrm{TiO}_{2}$ nanoparticles [58]. $\mathrm{ZnO}$ incorporated PVA/Starch/Chitosan hydrogel membranes have been synthesized by freezing thawing cycle. These membranes have good flexibility, porosity, adequate mechanical strength and tear resistance [59]. Pectin grafted poly-2-acrylamide-2-methyl-propane sulphonic acid-co-acrylamide/ZnO nanocomposite hydrogel through microwave irradiation method. $\mathrm{ZnO}$ nanoparticles increased the absorption capacity of the polymeric hydrogel [60]. In literature, Guar $\mathrm{Gum} / \mathrm{Al}_{2} \mathrm{O}_{3}$ and Guar $\mathrm{Gum} / \mathrm{CuO}$ nanocomposites were synthesized by sol-gel method. The red shift shows strong interaction between polymer matrix and aluminium oxide nanoparticles [61, 62]. $\mathrm{CuO}$ based nanoparticles show negligible cytotoxicity and good thermal stability and prove to be good candidates for controlled drug release system [62]. Sahoo et al. have synthesized Guar Gum coated iron oxide $\left(\mathrm{Fe}_{3} \mathrm{O}_{4}\right) \quad$ nanocomposites through coprecipitation method. These were good adsorbents for removal and enrichment of organic dye Congo red from aqueous medium [63].

Iron oxide, apart from acquiring nanodimensions, also possesses magnetic behavior and is sensitive to the external magnetic field. When incorporated into a gel matrix inculcates magnetic responsive behavior into parent matrix. Co-precipitation method is the conventional method adopted for synthesis of magnetic nanoparticles and possesses high magnetic sensitivity against external field. Pourjavadi et al. have fabricated magnetic nanocomposite hydrogels of starchgraft-poly (acrylic acid) in the presence of $\mathrm{Fe}_{3} \mathrm{O}_{4} / \mathrm{SiO}_{2}$ nanoparticles through in situ cross linking polymerization. $\quad \mathrm{Fe}_{3} \mathrm{O}_{4} / \mathrm{SiO}_{2}$ nanoparticles decline the water holding capacity of nanocomposite hydrogel as compared to nonmagnetic hydrogel because $\mathrm{Fe}_{3} \mathrm{O}_{4} / \mathrm{SiO}_{2}$ nanoparticles act as auxillary crosslinkers as well as copolymers [64]. Polyelectrolytic Xanthan gum/Chitosan/ $/ \mathrm{Fe}_{3} \mathrm{O}_{4}$ based magnetically responsive bionanocomposite hydrogels have been fabricated through in situ ionic complexation using D$(+)$-glucuronic acid and $\delta$-lactone as a green acidifying agent. Functional groups present on gel network contribute to the improved stability of magnetic nanoparticles. Cell adhesion, storage modulus and mechanical properties were improved by incorporation of $\mathrm{Fe}_{3} \mathrm{O}_{4}$ magnetic nanoparticles [65]. Maghemite $\left(\Upsilon-\mathrm{Fe}_{2} \mathrm{O}_{3}\right) /$ Iota carrageenan based magnetic nanocomposite hydrogels have been designed by Maciel et al. The nanocomposites display good ferromagnetic behavior, spherical morphology, good thermal stability, good swelling ability and particle size of $710 \mu \mathrm{m}$ [66]. Iota-carrageen and $\Upsilon-\mathrm{Fe}_{2} \mathrm{O}_{3}$ magnetic nanocomposites were synthesized by Raman et al. through sonication. The electrostatic interaction between the sulphate groups of carrageenan and $\Upsilon-\mathrm{Fe}_{2} \mathrm{O}_{3}$ stabilized the nanoparticles. The sulphate groups present on the carrageenan were also responsible for the improved physical properties [66, 67]. 
Nanoparticle concentration strongly influences the surface charge, gel forming ability and magnetic properties of nanocomposites which further can be exploited to fit into appropriate applications [67]. Cobalt ferrite $\left(\mathrm{CoFeO}_{4}\right)$ nanoparticles coated with 3-amino propyl trimethoxy silane could be easily loaded on to carboxy-methylcellulose to obtain nanocomposite hydrogels [68]. Bisht et al. used supercritical carbon dioxide assisted green chemical technology to synthesize starch/ $\mathrm{Fe}_{3} \mathrm{O}_{4}$ nanocomposites. Magnetic nanoparticles have crystalline structure with size of $16 \mathrm{~nm}$ range and nanocomposites possess good adsorption capacity as compared to nanoparticles alone [69]. $\mathrm{Fe}_{3} \mathrm{O}_{4}$ enclosed nanocomposite hydrogels were obtained in the presence of chitosan matrix using an in situ co-precipitation method in alkali medium. High chitosan concentration prevents formation of iron oxide nanoparticles, instead ferric hydroxide was formed. The presence of magnetic nanoparticles increased elastic modulus of chitosan ferrogels [70].

\section{Cellulose Nano Crystals (CNC) and Cellulose Fibres Based Nanocomposite Hydrogels}

In literature, Cellulose nanocrystals and cellulose fibres have been exploited as reinforcing materials for the synthesis of polysaccharide based nanocomposite hydrogels. Rao et al. have prepared CNC reinforced xanthum gum/chitosan bionanocomposites using D-(+)-Glucuronic acid and $\delta$-Lactone as green acidifying agents. These nanocomposite hydrogels have improved mechanical properties, good biocompatibility and good porous structure when compared with the xanthan gum and chitosan hydrogels without CNC. Porosity of gel networks attributes to the electrostatic interaction and hydrogen bonding between the functional groups present on the $\mathrm{CNC}$ and the polysaccharides. CNCs display their characteristic behavior in the concentration range of 2 to $10 \%$ [71]. Cellulose fiber (Grewia optiva) reinforced nanocomposite blend films of starch/PVA have been fabricated by casting method using citric acid as plastisizer and glutaraldehyde as crosslinker. These is clear improvement in physicochemical properties such as mechanical properties, tensile strength, elongation percentage, degree of swelling, biodegradability and cell adhesion of nanocomposite blend films as compared with starch/PVA blend films without reinforcing material Grewia optiva. Mixing time, concentration of citric acid, glutaraldehyde and Grewia optiva control all their physicochemical properties [72]. Similar behavior is also observed in PVA (polyvinyl alcohol)/chitosan/CNC bionanocomposite films. The tensile strength shows drastic increase from 98.4 to $395 \mathrm{MPa}$ when CNC content increased from 0 to 1 weight $\%$. The oxygen permeability of the CNC reinforced blend films increases due to the formation of pores [73]. These properties favor their use in fabrication of wound dressing scaffolds. $\mathrm{CNC} /$ Halloysite reinforced nanocomposite scaffolds of sodium alginate and xanthum gum as hydrogel matrix have been synthesized by freeze drying. Incorporation of $\mathrm{CNC}$ and halloysite show improved mechanical, compressive and thermal properties of these scaffolds when compared with those without $\mathrm{CNC} /$ Halloysite but in turn decline the water holding capacity. The compressive properties of nanocomposite scaffolds were improved in both wet and dry state [74].

\section{Carbon Nanotubes (CNT)/Graphene Oxide (GO)/Graphene Based Nanocomposite Hydrogels}

Different forms of carbon in the form of graphene, graphene oxide and carbon nanotubes (CNT) are also used as reinforcing materials for nanocomposite hydrogel fabrications. All these forms have excellent properties such as high electrical conductivity at room temperature, long term environmental stability, good electrochemical activity and biocompatibility. CNTs, when incorporated into polysaccharide matrix, modulate their inherent properties [75]. CNTs/graphene need functionalization through chemical or radiation treatment to improve their binding affinity to polysaccharide systems [75]. Bibi et al. have incorporated $\gamma$-radiated carbon nanotubes into silane crosslinked chitosan/PVA polymer matrix to prepare a green nanocomposite. CNTs improve physical 
properties but drastically decrease the swelling profile of hydrogel systems [76]. This behavior favors their use as implants where stability is the more crucial property to be kept in consideration. Acrylic acid functionalized K-carrageenan hydrophilic networks when reinforced with multiwalled carbon nanotubes (MCNT) improve swelling and adsorption behavior. Concentration of reinforcing material influences the adsorption capacity. The adsorption capacity decreased with decrease in $\mathrm{pH}$, increase in MCNTs concentration beyond $.04 \%$, in agitation time of more than 90 min [77]. GO/Cellulose Nano Crystals and GO/Urea cellulose nanocomposites display improved viscosity, thermal stability, mechanical strength and tensile strength [78, 79]. GO/Chitosan nanocomposite has strong interaction between the functional groups of two components and thus increases mechanical strength in both wet and dry state, storage modulus and thermal stability [80]. Starch/Graphene nanocomposite films when prepared through solution castings have improved tensile strength with increase in the graphene content and decline in moisture uptake [81].

\section{Clay Nanocomposite Hydrogels}

Clay also acts as an excellent reinforcing material for the synthesis of nanocomposites. Montmorillonite [82], saponite [83] and hectorite [84] are clays most commonly used in synthesis of nanocomposites. In situ polymerization [85], solution dispersion [86] and fusion intercalation [87] are some methods adopted for synthesis of polysaccharide/clay nanocomposite hydrogels. Silane modified nanoclay when crosslinked with functionalized starch (starch phthalate) notably improve the compressive modulus and strength of hydrogel upto twice by the addition of nanoclay. The increase in the mechanical properties was due to interaction between the amine groups present on the nanoclay and the hydroxyl and ester groups present on the modified starch [88]. Zhang et al. prepared superabsorbent hydrogels by graft polymerization of acrylic acid and AMPS (2-acrylamido-2-methyl propane sulphonic acid) onto xylan and montmorrilonite, an inorganic clay. These superabsorbents have high compressive modulus, swelling capacity and multistimuli responsive behavior as well as tolerance to salt due to the incorporation of ionic and nonionic groups [89]. Menon et al. have incorporated nanoclay cloisite into the guar gum grafted with polyacrylic acid semisynthetic matrix through microwave irradiation. Cloisite improved mechanical properties and thermal stability of the nanocomposite. Swelling capacity of cloisite embedded nanocomposite was maximum when the concentration of cloisite was $2 \%$. With further increase in the clay concentration the swelling capacity declines as the clay itself starts acting as auxillary crosslinker [90]. Guar gum/montmorillonite enclosed nanocomposites have improved mechanical, tensile strength and adsorption properties [91]. Silane modified nanoclay has also been used to prepare acrylic acid grafted guar gum nanocomposites through microwave irradiation. These prepared nanocomposites were $\mathrm{pH}$ sensitive and have good swelling capacity [92]. Guar gum-g-poly (sodium acrylate)/Na-montmorillonite superadsorbent nanocomposites were also prepared by grafted polymerization in aqueous medium. Montmorillonite was exfoliated and evenly dispersed in guar gum-g-poly (sodiumacrylate) matrix [93]. Starch, xanthum gum and nanoclay (sodium montmorillonite) based biodegradable nanocomposite films can also be synthesized by extrusion using glycerol as plasticizer. Nanoclay addition generates more transparent and resistant films with lower water permeability and lower water sorption capacities and xanthum gum addition improves the elongation properties of starch films [94].

Polysaccharide based nanocomposite hydrogels have applications in the field of wound dressing [43, 44, 46, 49, 52, 58, 95, 96], drug delivery [53, 71, 91, 97-99], tissue engineering $[65,88,100]$, bioremediation of toxic metal ions and dyes [101-103], biosensors and photocatalysis.

\section{CONCLUSION}

Reinforcing materials such as metallic nanoparticles, metal oxides, CNTs, clay and cellulosic fibres improve physical properties, especially mechanical and tensile behavior, which favors their applicability as tissue 
engineering materials. At the same time these materials also incorporate antibacterial, antimicrobial, antioxidant, optical and electrical properties in polymeric matrix which pave the way to apply such advanced materials to biomedical applications with ease. Nanocomposite hydrophilic systems have drastically improved and provided new route for current biomedical research as they have resulted into double potential hydrophilic systems.

\section{REFERENCES}

1. Hoffman AS. Hydrogels for Biomedical Applications. AdvDrug Deliv Rev. 2012; 64: 18-23p.

2. Padil VVT, Wacławek S, Černík M. Green Synthesis: Nanoparticles and Nanofibres Based on Tree Gums for Environmental Applications. Ecol Chem Eng S. 2016; 23(4): 533-557p.

3. Shah M, Fawcett D, Sharma S, Tripathy S, Poinern G. Green Synthesis of Metallic Nanoparticles via Biological Entities. Materials. 2015; 8(11): 7278-7308p.

4. Padil VVT, Černík M. Green Synthesis of Copper Oxide Nanoparticles Using Gum Karaya as a Biotemplate and Their Antibacterial Application. Int $J$ Nanomedicine. 2013; 8: 889p.

5. Zare-Akbari, Z, Farhadnejad H, FurughiNia B, Abedin S, Yadollahi M, KhorsandGhayeni M. PH-Sensitive Bionanocomposite Hydrogel Beads Based on Carboxymethyl Cellulose/ZnO Nanoparticle as Drug Carrier. IntJBiol Macromol. 2016; 93: 1317-1327p.

6. Beachley V, Ma G, Papadimitriou C, Gibson M, Corvelli M, Elisseeff J. Extracellular Matrix ParticleGlycosaminoglycan Composite Hydrogels for Regenerative Medicine Applications. $J$ Biomed Mater Res A. 2018; 106(1): 147-159p.

7. Lee KY, Mooney DJ. Alginate: Properties and Biomedical Applications. ProgPolym Sci. 2012; 37(1): 106-126p.

8. Rinaudo M. Chitin and Chitosan: Properties and Applications. ProgPolym Sci. 2006; 31(7): 603-632p.

9. Kumar MNR. A Review of Chitin and Chitosan Applications. ReactFunct Polym. 2000; 46(1): 1-27p.
10. Kumar MR, Muzzarelli R, Muzzarelli C, Sashiwa H, Domb AJ. Chitosan Chemistry and Pharmaceutical Perspectives. ChemRev. 2004; 104(12): 6017-6084p.

11. Imeson AP. Carrageenan. Handbook of Hydrocolloids. 2000; 87-102p.

12. Necas J, Bartosikova L. Carrageenan: A Review. Vet Med Czech. 2013; 58(4): 187-205p.

13. Klemm D, Heublein B, Fink HP, Bohn A. Cellulose: Fascinating Biopolymer and Sustainable Raw Material. Angew Chem International Edition. 2005; 44(22): 3358-3393p.

14. Tunç S, Duman O. Preparation and Characterization of Biodegradable Methyl Cellulose/Montmorillonite Nanocomposite Films. Appl Clay Sci. 2010; 48(3): $414-424 \mathrm{p}$.

15. Ghanbarzadeh B, Almasi H, Entezami AA. Physical Properties of Edible Modified Starch/Carboxymethyl Cellulose Films. InnovFood Sci Emerg Technol. 2010; 11(4): 697-70p.

16. Defaye J, Wong E. Structural Studies of Gum Arabic, the Exudate Polysaccharide from Acacia senegal. Carbohydr Res. 1986; 150(1): 221-231p.

17. Chudzikowski RJ. Guar Gum and Its Applications. J Soc Cosmet Chem. 1971; 22(1): 43p.

18. Wang X, Wang J, Zhang J, Zhao B, Yao J, Wang Y. Structure-Antioxidant Relationships of Sulfated Galactomannan from Guar Gum. Int J Biol Macromol. 2010; 46(1): 59-66p.

19. Mirhosseini H, Amid BT. A Review Study on Chemical Composition and Molecular Structure of Newly Plant Gum Exudates and Seed Gums. Food Res Int. 2012; 46(1): 387-398p.

20. Misaki A. Structural Aspects of Some Functional Polysaccharides. In Food Hydrocolloids. Boston, MA: Springer; 1994; 1-19p.

21. Eliasson AC, editor. Starch in Food: Structure, Function and Applications. CRC Press; 2004.

22. Yu H, Huang Q. Enhanced in vitro AntiCancer Activity of Curcumin Encapsulated in Hydrophobically Modified Starch. Food Chem. 2010; 119(2): 669-674p. 
23. Tischer CA, Iacomini M, Gorin PA. Structure of the Arabinogalactan from Gum Tragacanth (Astralagus gummifer). CarbohydrRes. $\quad 2002 ; \quad 337(18)$ : 1647-1655p.

24. Aspinall GO, Baillie J. 318. Gum tragacanth. Part I. Fractionation of the Gum and the Structure of Tragacanthic Acid. J Chem Soc (Resumed). 1963; 1702-1714p.

25. Wang W. Tragacanth and Karaya. Editor(s): Phillips, Glyn O.; Williams, Peter A. Handbook of Hydrocolloids (2000), 231-246. Publisher : Woodhead Publishing Ltd.. Cambridge. UK.

26. Izydorczyk M, Cui SW, Wang Q. Polysaccharide Gums: Structures, Functional Properties, and Applications. Food Carbohydrates: Chemistry, Physical Properties, and Applications. 2005; 293-299p.

27. An J, Ji Z, Wang D, Luo Q, Li X. Preparation and Characterization of Uniform-Sized Chitosan/Silver Microspheres with Antibacterial Activities. Mater Sci Eng C. 2014; 36: 33-41p.

28. Wang C, Gao X, Chen Z, Chen Y, Chen H. Preparation, Characterization and Application of Polysaccharide-Based Metallic Nanoparticles: A Review. Polymers. 2017; 9(12): 689p.

29. Han IK, Chung T, Han J, Kim YS. Nanocomposite Hydrogel Actuators Hybridized with Various Dimensional Nanomaterials for Stimuli Responsiveness Enhancement. Nano Converg. 2019; 6:18p.

30. Deng Z, Guo Y, Zhao X, Ma PX, Guo B. Multifunctional Stimuli-Responsive Hydrogels with Self-Healing, High Conductivity, and Rapid Recovery through Host-Guest Interactions. Chem Mater. 2018; 30(5): 1729-1742p.

31. Yang J, Liu S, Xiao Y, Gao G, Sun Y, Guo Q, Fu J. Multi-Responsive Nanocomposite Hydrogels with High Strength and Toughness. J Mater Chem B. 2016; 4(9): 1733-1739p.

32. Iglesias D, Bosi S, Melchionna M, Da Ros T, Marchesan S. The Glitter of Carbon Nanostructures in Hybrid/Composite
Hydrogels for Medicinal Use. CurrTopMed Chem. 2016; 16(18): 1976-1989p.

33. Sengur-Tasdemir R, Mokkapati VR, Koseoglu-Imer DY, Koyuncu I. Effect of Polymer Type on Characterization and Filtration Performances of Multi-Walled Carbon Nanotubes (MWCNT)-COOHBased Polymeric Mixed Matrix Membranes. EnvironTechnol. 2018; 39(10): 1226-1237p.

34. RafieianS, Mirzadeh H, Mahdavi H, Masoumi ME. A Review on Nanocomposite Hydrogels and Their Biomedical Applications. Sci Eng Compos Mater. 2019;26(1): 154-174p.

35. Ahmed J. Recent Advances of Novel Materials for 3D/4D Printing in Biomedical Applications. In $3 D$ and $4 D$ Printing in Biomedical Applications: Process Engineering and Additive Manufacturing. 2019; 239-271p, WileyVCH Verlag GmbH\&Co.KGaA .

36. Juby KA, Dwivedi C, Kumar M, Kota S, Misra HS, Bajaj PN. Silver NanoparticleLoaded PVA/Gum Acacia Hydrogel: Synthesis, Characterization and Antibacterial Study. CarbohydrPolym. 2012; 89(3): 906-913p.

37. Jaouen V, Brayner R, Lantiat D, Steunou $\mathrm{N}$, Coradin $\mathrm{T}$. In situ Growth of Gold Colloids within Alginate Films. Nanotechnology. 2010; 21(18): 185605p.

38. Arora D, Dhanwal V, Nayak D, Saneja A, Amin H, UrRasool R, Goswami A. Preparation, Characterization and Toxicological Investigation of Copper Loaded Chitosan Nanoparticles in Human Embryonic Kidney HEK-293 Cells. Mater Sci Eng C. 2016; 61: 227-234p.

39. Laudenslager MJ, Schiffman JD, Schauer CL. Carboxymethyl Chitosan as a Matrix Material for Platinum, Gold, and Silver Nanoparticles. Biomacromolecules. 2008; 9(10): 2682-2685p.

40. Sharma R, Singh N, Tiwari S, Tiwari SK, Dhakate SR. Cerium Functionalized PVA-Chitosan Composite Nanofibers for Effective Remediation of Ultra-Low Concentrations of $\mathrm{Hg}$ (II) in Water. Rsc Adv. 2015; 5(22): 16622-16630p. 
41. Shrifian-Esfahni A, Salehi MT, NasrEsfahni M, Ekramian E. ChitosanModified Superparamgnetic Iron Oxide Nanoparticles: Design, Fabrication, Characterization and Antibacterial Activity. Chemik. 2015; 69(1): 19-32p.

42. Karthiga Devi G, Senthil Kumar P, Sathish Kumar K. Green Synthesis of Novel Silver Nanocomposite Hydrogel Based on Sodium Alginate as an Efficient Biosorbent for the Dye Wastewater Treatment: Prediction of Isotherm and Kinetic Parameters. Desalin Water Treat. 2016; 57(57): 27686-27699p.

43. Rao KM, Kumar A, Haider A, Han SS. Polysaccharides Based Antibacterial Polyelectrolyte Hydrogels with Silver Nanoparticles. Mater Lett. 2016; 184: 189-192p.

44. Rao KM, Kumar A, Rao KSVK, Haider A, Han SS. Biodegradable Tragacanth Gum Based Silver Nanocomposite Hydrogels and Their Antibacterial Evaluation. J Polym Environ. 2018; 26(2): 778-788p.

45. Sanyasi S, Majhi RK, Kumar S, Mishra M, Ghosh A, Suar M, Goswami L. Polysaccharide-Capped Silver Nanoparticles Inhibit Biofilm Formation and Eliminate Multi-Drug-Resistant Bacteria by Disrupting Bacterial Cytoskeleton with Reduced Cytotoxicity towards Mammalian Cells. SciRep. 2016; 6: 24929p.

46. Agnihotri S, Mukherji S, Mukherji S. Antimicrobial Chitosan-PVA Hydrogel as a Nanoreactor and Immobilizing Matrix for Silver Nanoparticles. Appl Nanosci. 2012; 2(3): 179-188p.

47. Krstić J, Spasojević J, Radosavljević A, Šiljegovć M, Kačarević-Popović Z. Optical and Structural Properties of Radiolytically in situ Synthesized Silver Nanoparticles Stabilized by Chitosan/Poly (Vinyl Alcohol) Blends. Radiat Phys Chem. 2014; 96: 158-166p.

48. Abdullah MF, Ghosh SK, Basu S, Mukherjee A. Cationic Guar Gum Orchestrated Environmental Synthesis for Silver Nano-Bio-Composite Films. CarbohydrPolym. 2015; 134: 30-37p.
49. Padil VVT, Nguyen NH, Ševců A, Černík M. Fabrication, Characterization, and Antibacterial Properties of Electrospun Membrane Composed of Gum Karaya, Polyvinyl Alcohol, and Silver Nanoparticles. J Nanomater. 2015; 2015: 9p.

50. Djerahov L, Vasileva P, Karadjova I, Kurakalva RM, Aradhi KK. Chitosan Film Loaded with Silver NanoparticlesSorbent for Solid Phase Extraction of $\mathrm{Al}$ (III), Cd (II), Cu (II), Co (II), Fe (III), Ni (II), $\mathrm{Pb}$ (II) and $\mathrm{Zn}$ (II). CarbohydrPolym. 2016; 147: 45-52p.

51. Cano A, Cháfer M, Chiralt A, GonzálezMartínez C. Development and Characterization of Active Films Based on Starch-PVA, Containing Silver Nanoparticles. Food Packag Shelf Life. 2016; 10: 16-24p.

52. SinghB, KumarA, SinghB, Rajneesh. Development of Silver Particle Impregnated Hydrogelby Radiation Induced Crosslinking for Wound Dressing Applications. American Journal of Drug Delivery and Therapeutics (AJDDT). 2018; 5(1): 1-7p.

53. Rao KM, Kumar A, Suneetha M, Han SS. $\mathrm{pH}$ and Near-Infrared Active; ChitosanCoated Halloysite Nanotubes Loaded with Curcumin-Au Hybrid Nanoparticles for Cancer Drug Delivery. IntJBiol Macromol. 2018; 112: 119-125p.

54. Giammanco GE, Carrion B, Coleman RM, Ostrowski AD. Photoresponsive Polysaccharide-Based Hydrogels with Tunable Mechanical Properties for Cartilage Tissue Engineering. ACS Appl Mater Interfaces. 2016; 8(23): 14423-14429p.

55. Al-Enizi AM, Ahamad T, Al-hajji AB, Ahmed J, Chaudhary AA, Alshehri SM. Cellulose Gum and Copper Nanoparticles Based Hydrogel as Antimicrobial Agents against Urinary Tract Infection (UTI) Pathogens. IntJBiol Macromol. 2018; 109: 803-809p.

56. Muraleedaran K, Mujeeb VA. Applications of Chitosan Powder with in situ Synthesized Nano ZnO Particles as an Antimicrobial Agent. IntJBiol Macromol. 2015; 77: 266-272p. 
57. Archana D, Singh BK, Dutta J, Dutta PK. Chitosan-PVP-Nano Silver Oxide Wound Dressing: in vitro and in vivo Evaluation. IntJBiol Macromol. 2015; 73: 49-57p.

58. Fan X, Chen K, He X, Li N, Huang J, Tang K, Wang F. Nano-TiO2/CollagenChitosan Porous Scaffold for Wound Repairing. IntJBiol Macromol. 2016; 91: 15-22p.

59. Baghaie S, Khorasani MT, Zarrabi A, Moshtaghian J. Wound Healing Properties of PVA/Starch/Chitosan Hydrogel Membranes with Nano Zinc Oxide as Antibacterial Wound Dressing Material. $J$ Biomater Sci Polym Ed. 2017; 28(18): 2220-2241p.

60. Kodoth AK, Ghate VM, Lewis SA, Badalamoole V. Application of Pectin-Zinc Oxide Hybrid Nanocomposite in the Delivery of a Hydrophilic Drug and a Study of Its Isotherm, Kinetics and Release Mechanism. IntJBiol Macromol. 2018; 115: 418-430p.

61. Pathani D, Katwal R, Sharma G, Naushad M, Khan MR, Ala'a H. Novel Guar Gum/Al2O3 Nanocomposite as an Effective Photocatalyst for the Degradation of Malachite Green Dye. IntJBiol Macromol. 2016; 87: 366-374p.

62. Sharma G, Katwal R. Fabrication, Characterization and Cytotoxicity of Guar Gum/Copper Oxide Nanocomposite: Efficient Removal of Organic Pollutant. In Materials Science Forum. Vol. 842. Trans Tech Publications;2016; 88-102p, Switzerland.

63. Sahoo JK, Kumar A, Rath J, Mohanty T, Dash P, Sahoo H. Guar Gum-Coated Iron Oxide Nanocomposite as an Efficient Adsorbent for Congo Red Dye. DesalinWater Treat. 2017; 95: 342-354p.

64. Pourjavadi A, Hosseini SH, Seidi F, Soleyman R. Magnetic Removal of Crystal Violet from Aqueous Solutions Using Polysaccharide-Based Magnetic Nanocomposite Hydrogels. Polym Int. 2013; 62(7): 1038-1044p.

65. Rao KM, Kumar A, Han SS. Polysaccharide-Based Magnetically Responsive Polyelectrolyte Hydrogels for Tissue Engineering Applications. J Mater Sci Technol. 2018; 34(8): 1371-1377p.
66. Maciel DJ, de Mello Ferreira IL, da Costa GM, da Silva MR. Nanocomposite Hydrogels Based on Iota-Carrageenan and Maghemite: Morphological, Thermal and Magnetic Properties. Eur Polym J. 2016; 76: 147-155p.

67. Raman M, Devi V, Doble M. Biocompatible 1-Carrageenan- $\gamma$ Maghemite Nanocomposite for Biomedical Applications-Synthesis, Characterization and in vitro Anticancer Efficacy. JNanobiotechnol. 2015; 13(1): $18 \mathrm{p}$.

68. Finetti F, Terzuoli E, Donnini S, Uva M, Ziche M, Morbidelli L. Monitoring Endothelial and Tissue Responses to Cobalt Ferrite Nanoparticles and Hybrid Hydrogels. PloS One. 2016; 11(12): e0168727p.

69. Bisht G, Neupane S. Arsenic Removal through Supercritical Carbon DioxideAssisted Modified Magnetic Starch (Starch-- $\mathrm{Fe}_{3} \mathrm{O}_{4}$ ) Nanoparticles. Nanotechnology for Environmental Engineering. 2018; 3(1): 8p.

70. Hernández R, Zamora-Mora V, SibajaBallestero M, Vega-Baudrit J, López D, Mijangos C. Influence of Iron Oxide Nanoparticles on the Rheological Properties of Hybrid Chitosan Ferrogels. JColloid Interface Sci. 2009; 339(1): 53-59p.

71. Rao KM, Kumar A, Han SS. Polysaccharide Based Bionanocomposite Hydrogels Reinforced with Cellulose Nanocrystals: Drug Release and Biocompatibility Analyses. IntJBiol Macromol. 2017; 101: 165-171p.

72. Priya B, Gupta VK, Pathania D, Singha AS. Synthesis, Characterization and Antibacterial Activity of Biodegradable Starch/PVA Composite Films Reinforced with Cellulosic Fibre. CarbohydrPolym. 2014; 109: 171-179p.

73. Azizi S, Ahmad MB, Ibrahim NA, Hussein MZ, Namvar F. Preparation and Properties of Poly (Vinyl Alcohol)/Chitosan Blend Bio-Nanocomposites Reinforced by Cellulose Nanocrystals. Chinese J Polym Sci. 2014; 32(12): 1620-1627p.

74. Kumar A, Rao KM, Han SS. Development of Sodium Alginate-Xanthan Gum Based 
Nanocomposite Scaffolds Reinforced with Cellulose Nanocrystals and Halloysite Nanotubes. Polym Test. 2017; 63: 214-225p.

75. Pati Manoj Kumar, Puspalata Pattojoshi, Gouri Sankar Roy. Synthesis of GrapheneBased Nanocomposite and Investigations of Its Thermal and Electrical Properties. Journal of Nanotechnology. 2016; 2016: Article ID 5135420: 9p.

76. Bibi S, Yasin T, Hassan S, Riaz M, Nawaz M. Chitosan/CNTs Green Nanocomposite Membrane: Synthesis, Swelling and Polyaromatic Hydrocarbons Removal. Mater Sci Eng C. 2015; 46: 359-365p.

77. Hosseinzadeh H. Synthesis of Carrageenan/Multi-Walled Carbon Nanotube Hybrid Hydrogel Nanocomposite for Adsorption of Crystal Violet from Aqueous Solution. Pol J Chem Technol. 2015; 17(2): 70-76p.

78. Fryczkowska B, Wiechniak K. Preparation and Properties of Cellulose Membranes with Graphene Oxide Addition. Pol $J$ Chem Technol. 2017; 19(4): 41-49p.

79. Chen X, Zhou S, Zhang L, You T, Xu F. Adsorption of Heavy Metals by Graphene Oxide/Cellulose Hydrogel Prepared from $\mathrm{NaOH} / \mathrm{Urea}$ Aqueous Solution. Materials. 2016; 9(7): 582p.

80. El Rouby WM, Farghali AA, Sadek MA, Khalil WF. Fast Removal of Sr (II) From Water by Graphene Oxide and Chitosan Modified Graphene Oxide. J Inorg Organomet Polym Mater. 2018;28 (6), pp. 2336-2349.

81. Bin-Dahman OA, Rahaman M, Khastgir D, Al-Harthi MA. Electrical and Dielectric Properties of Poly (Vinyl Alcohol)/Starch/Graphene

Nanocomposites. Can J Chem Eng. 2018; 96(4): 903-911p.

82. Islam MS, Rahaman MS, Yeum JH. Electrospun Novel Super-Absorbent Based on Polysaccharide-Polyvinyl Alcohol-Montmorillonite Clay Nanocomposites. CarbohydrPolym. 2015; 115: 69-77p.

83. Zhen W, Zheng Y. Synthesis, Characterization, and Thermal Stability of Poly (Lactic Acid)/Zinc Oxide Pillared Organic Saponite Nanocomposites via
Ring-Opening Polymerization of d, 1Lactide. Polym Adv Technol. 2016; 27(5): 606-614p.

84. Bhuyan B, Srivastava SK, Mittal V. Ethylene-co-Vinyl

Acetate/MWCNTs/Hectorite Elastomeric Nanocomposites: Characterization and Electrical Properties. JNanosciNanotechnol. 2018; 18(6): 4057-4064p.

85. Ozkose UU, Altinkok C, Yilmaz O, Alpturk O, Tasdelen MA. In-situ Preparation of Poly (2-Ethyl-2Oxazoline)/Clay Nanocomposites via Living Cationic Ring-Opening Polymerization. Eur Polym J. 2017; 88: 586-593p.

86. Etika KC, Liu L, Cox MA, Grunlan JC. Clay-Mediated Carbon Nanotube Dispersion in Poly (NIsopropylacrylamide). Colloids Surfaces A: Physicochem Eng Asp. 2016; 489: 19-26p.

87. Weng $\mathrm{Z}$, Wang J, Senthil $\mathrm{T}$, Wu L. Mechanical and Thermal Properties of ABS/Montmorillonite Nanocomposites for Fused Deposition Modeling 3D Printing. Mater Des. 2016; 102: 276-283p.

88. Ashamol A, Priyambika VS, Avadhani GS, Sailaja RRN. Nanocomposites of Crosslinked Starch Phthalate and Silane Modified Nanoclay: Study of Mechanical, Thermal, Morphological, and Biodegradable Characteristics. Starch-Stärke. 2013; 65(5-6): 443-452p.

89. Zhang S, Guan Y, Fu GQ, Chen BY, Peng F, Yao CL, Sun RC. Organic/Inorganic Superabsorbent Hydrogels Based on Xylan and Montmorillonite. J Nanomater. 2014; 2014: 2p.

90. Menon S, Deepthi MV, Sailaja RRN, Ananthapadmanabha GS. Study on Microwave Assisted Synthesis of Biodegradable Guar Gum Grafted Acrylic Acid Superabsorbent Nanocomposites. Indian J Adv Chem Sci. 2014; 2(2): 76-83p.

91. Dziadkowiec J. Guar Gum/Montmorillonite Nanocomposites and Their Potential Application in Drug Delivery. Doctoral Dissertation, Université d'Ottawa/University of Ottawa. 2016. 
92. Shruthi SB, Bhat C, Bhaskar SP, Preethi G, Sailaja RRN. Microwave Assisted Synthesis of Guar Gum Grafted Acrylic Acid/Nanoclay Superabsorbent Composites and Its Use in Crystal Violet Dye Absorption. Green and Sustainable Chemistry (GSC). 2016; 6(01): 11p.

93. Wang W, Wang A. Synthesis and Swelling Properties of Guar Gum-G-Poly (Sodium Acrylate)/Na-Montmorillonite Superabsorbent Nanocomposite. JCompos Mater. 2009; 43(23): 2805-2819p.

94. Melo CD, Garcia PS, Grossmann MVE, Yamashita F, Dall'Antônia LH, Mali S. Properties of Extruded Xanthan-StarchClay Nanocomposite Films. Braz Arch Biol Technol. 2011; 54(6): 1223-1333p.

95. Singh B, Varshney L, Francis S. Synthesis and Characterization of Tragacanth Gum Based Hydrogels by Radiation Method for Use in Wound Dressing Application. Radiat Phys Chem. 2017; 135: 94-105p.

96. Rinehart SJ, Campbell T, Burke KJ, Garcia B, Mlynarski A, Brain SJ, Keleher JJ. Synthesis and Characterization of a Chitosan/PVA Antimicrobial Hydrogel Nanocomposite for Responsive Wound Management Materials. $J$ Microb Biochem Technol. 2016; 8: 065-070p.

97. Kodoth AK, Ghate VM, Lewis SA, Badalamoole V. Application of Pectin-Zinc Oxide Hybrid Nanocomposite in the Delivery of a Hydrophilic Drug and a Study of Its Isotherm, Kinetics and Release Mechanism. IntJBiol Macromol. 2018; 115: 418-430p.

98. Zare-Akbari Z, Farhadnejad H, FurughiNia B, Abedin S, Yadollahi M, Khorsand-Ghayeni M. PH-Sensitive Bionanocomposite Hydrogel Beads Based on Carboxymethyl Cellulose/ZnO Nanoparticle as Drug Carrier. IntJBiol Macromol. 2016; 93: 1317-1327p.

99. Sadequi Mohammad, Shafiei F, Mohammadinasab E, Sadeghi H, Shasavari H. Biosuperabsorbent Hydrogel Based on Alginate-g-PolyAA/Kaolin Composite for Releasing Cefalexin Drug. Orient J Chem. 2014; 30(1): 285-290p.

100. Raghavendra GM, Jayaramudu T, Varaprasad K, Sadiku R, Ray SS, Raju KM. Cellulose-Polymer-Ag Nanocomposite Fibers for Antibacterial Fabrics/Skin Scaffolds. CarbohydrPolym. 2013; 93(2): 553-560p.

101. Jiao X, Gutha Y, Zhang W. Application of Chitosan/Poly (Vinyl Alcohol)/CuO (CS/PVA/CuO) Beads as an Adsorbent Material for the Removal of $\mathrm{Pb}$ (II) from Aqueous Environment. Colloids Surf B: Biointerfaces. 2017; 149:184-195p.

102. Zhou Y, Fu S, Zhang L, Zhan H, Levit MV. Use of Carboxylated Cellulose Nanofibrils-Filled Magnetic Chitosan Hydrogel Beads as Adsorbents for Pb (II). CarbohydrPolym. 2014; 101:75-82p.

103. Pour Zahra Sekhavat, Mousa Ghaemy. Removal of Dyes and Heavy Metal Ions from Water by Magnetic Hydrogel Beads Based on Poly (Vinyl Alcohol)/Carboxymethyl Starch-G-Poly (Vinyl Imidazole). RSC $A d v$. 2015; 5(79): 64106-64118p.

\section{Cite this Article}

Nisha Sharma, Vikrant Singh Rana. A Review on Polysaccharide Based Nanocomposite Hydrogel Systems Fabrication Using Diverse Reinforcing Materials. Journal of Polymer \& Composites. 2020; 8(1): 6-17p. 